\title{
The pitfalls of using the 2010 American college of rheumatology/European league against rheumatism (acr/ eular) classification criteria for diagnosis of rheumatoid arthritis
}

\author{
Alkhairi $\mathrm{B}^{1 *}$, Mohameden $\mathrm{M}^{2}$, Issa $\mathrm{S}^{1}$, Crager $\mathrm{K}^{1}$, Yuvienco $\mathrm{C}^{2}$ and Elzawawy $\mathrm{H}^{3}$ \\ ${ }^{1}$ Blake Medical Center, USA \\ ${ }^{2}$ University of California San Francisco Fresno, USA \\ ${ }^{3}$ Cleveland Clinic Florida, USA
}

\begin{abstract}
We report a case of a 63-year-old man with a history of monoarthritis, thought to have Rheumatoid Arthritis (RA) and treated with disease-modifying antirheumatic drugs (DMARDs). No clinical or serological improvement was observed. After five months synovectomy was performed. A foreign body was recovered, and synovial fluid analysis revealed a rare fungal infection, Phaeoacremonium sp. This is an educational case that reveals potential pitfalls of the specificity of using the current classification criteria for Rheumatoid Arthritis (RA) as a diagnostic tool in patients presenting with monoarthritis and highlights the need to continually reassess the diagnosis when there's inadequate response to treatment.
\end{abstract}

\section{Introduction}

In the absence of a gold standard test, the diagnosis of Rheumatoid Arthritis (RA) can be challenging. The first classification criteria from the American College of Rheumatology came in 1987, and it had low sensitivity and specificity for diagnosing early-stage disease [1,2]. Twenty-three years later, the ACR collaborated with the European League Against Rheumatism (EULAR) to come up with new criteria that are more sensitive and specific in diagnosis than the 1987 criteria [3-5].

\section{Case presentation}

A 63-year-old Caucasian male was referred to the rheumatology clinic for a four-year history of left fourth finger pain. The pain was in the proximal interphalangeal (PIP) joint, he noted worsening in the past 10 months, it was non-radiating, asymmetrical and worst with movement. It was accompanied by morning stiffness. The patient rated the pain as 8 out of 10 in severity. There was no numbness or tingling.

Past medical history included dyslipidemia and left hip osteoarthritis. Family history was irrelevant except that his father had Psoriasis. The patient doesn't smoke or drink alcohol. He does gardening. He was taking Lovastatin, ASA, and Ibuprofen-Famotidine at that time. Review of system was noncontributory. On physical exam, the proximal interphalangeal (PIP) joint of the left fourth finger showed tenderness and limited range of motion without erythema. Peripheral pulses and capillary refill were brisk and normal. Sensation was intact. There was no muscles atrophy.

$\mathrm{X}$-ray (Figure 1) showed periarticular erosions along the medial and lateral aspect of the head of the PIP joint, with severe fusiform soft tissue swelling at the level of PIP. This indicated inflammatory changes in the joint. Laboratory testing showed elevated CRP 4.53 $\mathrm{mg} / \mathrm{L}(0-3 \mathrm{mg} / \mathrm{L})$ and elevated anticitrullinated protein antibodies (ACPA) $225 \mathrm{EU} / \mathrm{ml}(0-20 \mathrm{EU} / \mathrm{ml})$. Rheumatoid Factor (RF) was within normal range, $11.2 \mathrm{IU} / \mathrm{ml}(0-15 \mathrm{IU} / \mathrm{ml})$. Other serological markers and laboratory investigations were within normal limits.

The Patient was diagnosed with Rheumatoid Arthritis. He was started on Methotrexate (MTX) 15mg/week and received a Triamcinolone $10 \mathrm{mg}$ intraarticular injection in the joint. The patient had significant improvement with the local injection for five weeks, but he had recurrence of the pain and swelling after eight weeks. A decision was taken to start the patient on Etanercept $50 \mathrm{mg} / \mathrm{ml} /$ week and increase the MTX dose to $20 \mathrm{mg} /$ week. There was no significant improvement at the six-week follow up despite normalization of CRP to $2.4 \mathrm{mg} / \mathrm{L}$. ACPA was rechecked and was at a higher titer of $>250 \mathrm{EU} / \mathrm{ml}$. An MRI (Figure 2) was ordered to rule out alternative diagnosis, it showed large joint effusion involving the ring finger PIP joint with synovial enhancement associated with marrow edema and enhancement. There was surrounding soft tissue swelling as well. The patient was referred for a synovectomy which was performed a month later.

A foreign body was discovered during the surgery. The patient had a $0.4 \times 0.3 \times 0.2 \mathrm{~cm}^{3}$ splinter. Histopathology showed focal acute inflammation, fibrin deposition on the surface as well as intense lymphoplasmacytic infiltrates and focal foreign body granulomatous

${ }^{*}$ Correspondence to: Alkhairi B, MD, Internal Medicine Resident, Blake Medical Center, Bradenton, Florida, USA, E-mail: baker.alkhairy@gmail.com

Key words: rheumatoid arthritis, phaeoacremonium sp, monoathrtitis, plant thorn arthritis

Received: July 13, 2018; Accepted: July 23, 2018; Published: July 26, 2018 


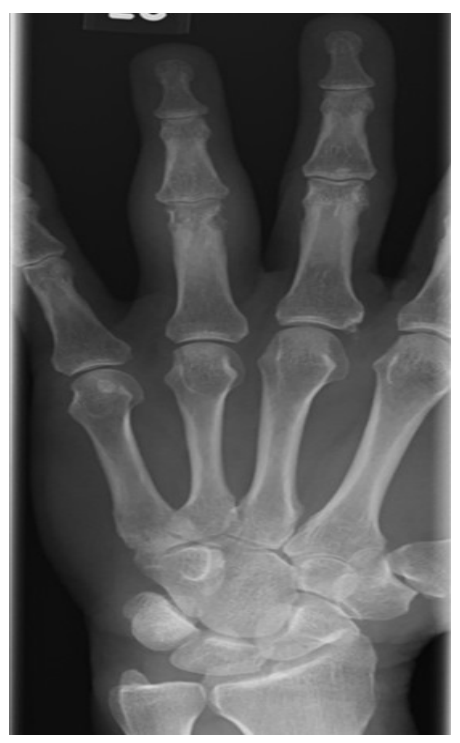

Figure 1. X-Ray image showing severe inflammatory changes and erosions

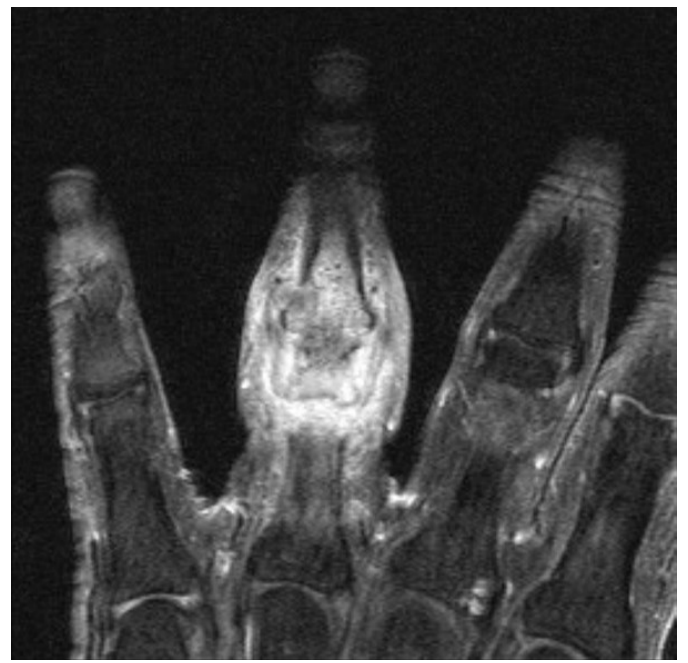

Figure 2. MRI showing large joint effusion involving the ring finger PIP joint with synovial enhancement associated with marrow edema and enhancement. Soft tissue swelling is noted as well

reaction. Cultures revealed a rare fungus, Phaeoacremonium sp. MTX and Humira were discontinued and Voriconazole $400 \mathrm{mg} / \mathrm{day}$ was started. The patient completed a six-months course of the voriconazole. Ultimately, the patient had complete resolution of the synovitis.

\section{Discussion}

Rheumatoid Arthritis (RA) is a potentially disabling, systemic autoimmune inflammatory disease of unknown etiology. It affects about $1 \%$ of the population and if not treated or if refractory to therapy it may result in joint destruction, disability, and loss of daily function and employment. Recent data suggest that early diagnosis and initiation of disease-modifying antirheumatic drugs (DMARDs) may reduce morbidity and mortality in RA patients [6]. However, the diagnosis of early RA has been a challenge for decades and clinical trials are still restricted by the difficulty of diagnosing early cases of RA because of lack of more accurate diagnostic criteria [3]. Therefore, the establishment of reliable and accurate diagnostic tools for early disease is of a paramount importance. Specially, when intensive treatment early in the disease may change or modify the natural history of RA and prevent destructive bony erosions [7].

The 1987 ACR classification criteria were used to diagnose RA for many years. Even though they had pooled sensitivity and specificity of (77-80\% and $33-77 \%$ respectively) in early disease and (79-80\% and 90-93\% respectively) in established disease, they were not meant to be used for diagnosis [1]. In 2010 a joint working group of the ACR and EULAR was therefore formed to develop a new approach for classification of RA. The working group investigated the factors that were thought to discriminate people with undifferentiated arthritis based on the likelihood of developing persistent and/or erosive disease which is the new paradigm of RA.

The ACR/EULAR report states that for RA to be classified as definite it requires the confirmed presence of synovitis in at least one joint, the absence of an alternative diagnosis for the observed arthritis, and a total score of at least 6 to be deemed RA [3-5] (Table 1). Our patient scored 7 . It is true that the 2010 criteria were initially formulated for classification and research purposes to recruit patients for clinical trials and testing of early RA treatment and it is true that the presence of ACPA antibodies is $94.5 \%$ specific for the diagnosis of RA [8]. Based on that evidence, the patient was diagnosed with RA and the decision was made to initiate treatment.

Of interest, psoriasis which can cause monoarthritis and elevated ACPA [9], was considered as a diagnosis, specially that the patient had a positive family history of psoriasis. Nevertheless, the treatment with MTX and Etanercept should have alleviated the patient's symptoms if that was the case.

Unfortunately, an unknown wooden splinter had introduced an opportunistic fungus, Phaeoacremonium sp, that's found in soil and woody plants [10], and mainly infects the immunocompromised. This infection can be serious and fatal if disseminated [11]. The patient's symptoms improved after a local steroid injection, however, it is not uncommon for septic arthritis to improve after a local steroid injection [12].

More studies outlining the diagnosis of early RA should be done. Fitting the ACR/EULAR 2010 criteria shouldn't necessary

Table 1. The 2010 American College of Rheumatology/European League Against Rheumatism classification criteria for RA

\begin{tabular}{|c|c|c|}
\hline \multicolumn{2}{|c|}{$\begin{array}{l}\text { The } 2010 \text { American College of Rheumatology/European League Against } \\
\text { Rheumatism Classification Criteria for RA }\end{array}$} & \multirow{2}{*}{$\begin{array}{c}\text { Score } \\
0\end{array}$} \\
\hline \multirow{5}{*}{ A. Joint involvement } & 1 Large Joint & \\
\hline & 2-10 Large joints & 1 \\
\hline & $1-3$ small joints & 2 \\
\hline & $\begin{array}{l}4-10 \text { small joints (with or without } \\
\text { involvement of large joints) }\end{array}$ & 3 \\
\hline & $>10$ joints (at least one small joint) & 5 \\
\hline \multirow{3}{*}{$\begin{array}{l}\text { B. Serology (at least } 1 \text { test result is needed } \\
\text { for classification) }\end{array}$} & Negative RF and negative ACPA & 0 \\
\hline & $\begin{array}{l}\text { Low-positive RF or low-positive } \\
\text { ACPA }\end{array}$ & 2 \\
\hline & $\begin{array}{l}\text { High-positive RF or high-positive } \\
\text { ACPA }\end{array}$ & 3 \\
\hline \multirow{2}{*}{$\begin{array}{l}\text { C. Acute-phase reactants (at least one test } \\
\text { result is needed for classification) }\end{array}$} & Normal CRP and normal ESR & 0 \\
\hline & Abnormal CRP or abnormal ESR & 1 \\
\hline \multirow{2}{*}{ D. Duration of symptoms } & $<6$ weeks & 0 \\
\hline & $\geq 6$ weeks & 1 \\
\hline
\end{tabular}

Target population (Who should be tested?): Patients who:

1) have at least 1 joint with definite clinical synovitis (swelling)

2) with the synovitis not better explained by another disease

Classification criteria for RA (score-based algorithm: add score of categories A-D; a score of $6 / 10$ is needed for classification of a patient as having definite RA). 
be conclusive for a diagnosis of early RA or RA with a single joint involvement. In monoarthritis, it is recommended that the joint should be aspirated, and infections must be ruled out, regardless of the duration of symptoms and/or if they fit into any other diagnoses. Otherwise, drastic complications may occur. Also, if appropriate it has been suggested that High-Resolution Ultrasonography, can detect plant thorns [13] and foreign bodies and maybe they should be used as a first study to do in monoarthritis because of their practicality and convenience.

\section{Limitations}

The patient failed to mention any history of trauma, which he had. Had he mentioned it, a better differential diagnosis could have been made and perhaps synovial fluid could have been aspirated and analyzed.

\section{Conclusion}

This case points out a potential pitfall in the 2010 ACR/EULAR classification criteria for RA, when used as a diagnostic tool for diagnosing RA in patients with monoathritis.

Although some patients can present a challenge to treat, this case reinforce the need to continually reevaluate patients when they do no not respond to what would be an appropriate treatment.

\section{Conflict of Interest}

None Declared

\section{Disclosures}

None Declared

\section{References}

1. F Banal, M Dougados, C Combescure, Gossec L (2009) Sensitivity and specificity of the American College of Rheumatology 1987 criteria for the diagnosis of rheumatoid arthritis according to disease duration: a systematic literature review and meta-analysis. Ann Rheum Dis 68: 1184-1191. [Crossref]

2. Harrison BJ, Symmons DP, Barrett EM, Silman AJ (1998) The performance of the 1987 ARA classification criteria for rheumatoid arthritis in a population-based cohort of patients with early inflammatory polyarthritis. American Rheumatism Association. $J$ Rheumatol 25: 2324-2330. [Crossref]
3. Aletaha D, Neogi T, Silman AJ, Funovits J, Felson DT, et al. (2010) 2010 Rheumatoid arthritis classification criteria: an American College of Rheumatology/European League Against Rheumatism collaborative initiative. Ann Rheum Dis 69: 1580-1588. [Crossref]

4. Funovits J, Aletaha D, Bykerk V, Combe B, Dougados M, et al. (2010) The 2010 American College of Rheumatology/European League Against Rheumatism classification criteria for rheumatoid arthritis: methodological report phase I. Ann Rheum Dis 69: 1589-1595. [Crossref]

5. Neogi T, Aletaha D, Silman AJ, Naden RL, Felson DT, et al. (2010) The 2010 American College of Rheumatology/European League Against Rheumatism classification criteria for rheumatoid arthritis: Phase 2 methodological report. Arthritis Rheum 62: 25822591. [Crossref]

6. Van Nies JA, de Jong Z, van der Helm-van Mil AH, Knevel R, Le Cessie S, et al. (2010) Improved treatment strategies reduce the increased mortality risk in early RA patients. Rheumatology (Oxford) 49: 2210-2206. [Crossref]

7. Verstappen SM, Jacobs JW, Bijlsma JW, Heurkens AH, van Booma-Frankfort C, et al (2003) Five-year followup of rheumatoid arthritis patients after early treatment with disease-modifying antirheumatic drugs versus treatment according to the pyramid approach in the first year. Arthritis Rheum 48: 1797-1807. [Crossref]

8. Sauerland U, Becker H, Seidel M, Schotte H, Willeke P, et al. (2005) Clinical utility of the anti-CCP assay: experiences with 700 patients. Ann N Y Acad Sci 1050: 314-318. [Crossref]

9. Alenius GM, Berglin E, Rantapää Dahlqvist S (2006) Antibodies against cyclic citrullinated peptide (CCP) in psoriatic patients with or without joint inflammation. Ann Rheum Dis 65: 398-400. [Crossref]

10. Mostert L, Groenewald JZ, Summerbell RC, Robert V, Sutton DA, et al. (2005) Species of Phaeoacremonium Associated with Infections in Humans and Environmental Reservoirs in Infected Woody Plants. J Clin Microbiol 43: 1752-1767. [Crossref]

11. Colombier MA, Alanio A, Denis B, Melica G, Garcia-Hermoso D, et al. (2015) Dual Invasive Infection with Phaeoacremonium parasiticum and Paraconiothyrium cyclothyrioides in a Renal Transplant Recipient: Case Report and Comprehensive Review of the Literature of Phaeoacremonium Phaeohyphomycosis. J Clin Microbiol 53: 2084-2094. [Crossref]

12. Farrow L (2015) A systematic review and meta-analysis regarding the use of corticosteroids in septic arthritis. BMC Musculoskelet Disord 16: 241. [Crossref]

13. Tung CH, Chen YH, Lan HH, Hsieh TY, Chen DY, et al. (2007) Diagnosis of plantthorn synovitis by high-resolution ultrasonography: a case report and literature review. Clin Rheumatol 26: 849-851. [Crossref]

Copyright: $\odot 2018$ Alkhairi B. This is an open-access article distributed under the terms of the Creative Commons Attribution License, which permits unrestricted use, distribution, and reproduction in any medium, provided the original author and source are credited. 